\title{
EU, TERCEIRIZADA: O QUE FAZER COM A MINHA CARREIRA?
}

\section{I, OUTSOURCED: WHAT TO DO WITH MY CAREER?}

\section{SUELLEN CRISTINA DE SOUSA CHAVES}

Universidade Federal da Paraíba (UFPB)

Bacharel em Administração (UFPB)

Orcid: http://orcid.org/0000-0002-8567-6565 / E-mail: suellenchaves94@hotmail.com

Universidade Federal da Paraíba, Centro de Ciências Sociais

Aplicadas, Departamento de Administração

Cidade Universitária, s/n, Castelo Branco, João Pessoa/PB, CEP: 58051-900

\section{DIANA LUCIA TEIXEIRA-DE-CARVALHO}

Universidade Federal da Paraíba (UFPB)

Professora no PPG em Gestão Pública e Cooperação Internacional (UFPB)

Orcid: http://orcid.org/0000-0001-6454-8604 / E-mail: diana.carvalho@academico.ufpb.br

\section{ANA CAROLINA KRUTA DE ARAÚJO BISPO}

Universidade Federal da Paraíba (UFPB)

Professora no PPG em Administração e em Gestão Pública e Cooperação Internacional (UFPB)

Orcid: http://orcid.org/0000-0002-0664-8575 / E-mail: ana.kruta@academico.ufpb.br

Submissão: 27/05/2020. Revisão: 24/03/2021. Aceite: 25/07/2021. Publicação: 28/07/2021.

DOI: http://dx.doi.org/10.22277/rgo.v14i3.5524

\section{RESUMO}

O caso para ensino relata a história de Samara, uma funcionária terceirizada, que encontra situações de trabalho excludentes, sobretudo do ponto de vista da gestão de pessoas, em ambas as empresas que assumem o contrato de terceirização. Com isso, Samara se vê em um dilema de carreira, pois, ao mesmo tempo em que questiona a possibilidade de continuar cumprindo a função de terceira, tem ciência de que, na área em que atua, não há outras empresas na cidade de João Pessoa que possam absorver seu conhecimento profissional. Diante disso, o objetivo desse caso é abordar a gestão de pessoas no contexto da terceirização, enfatizando a necessidade de que ambas as organizações se comprometam a envolver os terceiros de maneira emocional, inconsciente e subjetiva, para que de fato esse tipo de arranjo profissional possa significar uma vantagem competitiva. Complementarmente, tem como propósito discutir, com base em âncoras individuais que direcionam o interesse profissional, possíveis decisões pessoais de carreira que podem ser necessárias à medida que dilemas se apresentem nos percursos dos indivíduos. Com isso, esse caso pode ser aplicado em disciplinas de gestão de pessoas, especificamente na discussão de elementos relacionados ao planejamento de carreira, em cursos de graduação e pós-graduação lato sensu em Administração.

Palavras-chave: Terceirização. Gestão de pessoas. Carreira. Caso para ensino.

Este é um artigo publicado em acesso aberto (Open Access) sob a licença Creative Commons Attribution, que permite uso, distribuição e reprodução em qualquer meio, sem restrições desde que o trabalho original seja corretamente citado. 


\begin{abstract}
The teaching case relates the story of Samara, a outsourced employee, who finds work situations that are excludents, especially from the point of view of people management, in both companies that assume the outsourcing contract. With this, Samara finds herself in a career dilemma, because, while questioning the possibility of continuing to fulfill the role of outsourced, she is aware that, in the area in which she operates, there are no other companies in the city of João Pessoa that can absorb her professional knowledge. Therefore, the objective of this case is to address people management in the context of outsourcing, emphasizing the need for both organizations to commit to involving outsourced in an emotional, unconscious, and subjective way, so that in fact this type of professional arrangement can mean a competitive advantage. In addition, it aims to discuss, based on individual anchors that direct professional interest, possible individual career decisions that may be necessary as dilemmas occur in the path of individuals. With this, this case can be applied in people management disciplines, specifically in the discussion of elements related to career planning, in undergraduate and graduate courses lato sensu in Administration.
\end{abstract}

Keywords: Outsourcing. People management. Career. Teaching case.

\title{
1 INTRODUÇÃO
}

Samara trabalhava como terceirizada desde 2014, mas se sentia cada vez mais desmotivada com esse contexto profissional. Certo dia, encontrou sua antiga professora de gestão de pessoas e, na expectativa de conseguir ajuda para tomar uma decisão que a estava afligindo, começou a relatar o que acontecera com ela nos últimos cinco anos:

Naquela noite do dia 05 de agosto de 2018, estávamos todos animados. Além de ser sexta, era o segundo dia útil do mês, ou seja, dia de receber salário. Os bares de João Pessoa já estavam lotados para o esperado happy hour, e nós, Amanda, Marcela, Gael e eu, saindo do trabalho, fomos desopilar em um deles. Entre uma conversa e outra, Amanda lembrou que na semana posterior nós iríamos completar quatro anos de formação daquela equipe para prestar serviços dentro da Enercon.

- Caramba! Semana que vem vamos completar quatro anos prestando serviços na Enercon. Parece que foi ontem, não é? - disse Amanda.

- É, passou muito rápido. Passamos por muitas situações complicadas - Marcela respondeu.

- Apesar de termos sido acolhidos muito bem pela equipe da Enercon, esse sentimento de não pertencer a nenhuma empresa é muito ruim - eu lembrei.

- Verdade! Lembra quando a Edifica LTDA não nos avisou sobre a mudança de plano de saúde e nós só ficamos sabendo por que Micael comentou? Isso foi a maior prova da falta de comunicação e controle de uma empresa com seus funcionários - Marcela disse.

- Nem me fale! Fico com muita raiva quando lembro que por causa disso perdi a chance de colocar minha irmã como dependente - Amanda respondeu.

A noite foi avançando e nós resolvemos ir embora. Na semana seguinte, em mais um dia de trabalho, Eliana, nossa coordenadora na Enercon, chegou com uma novidade:

- Bom dia pessoal, vocês estão sabendo da campanha de vacinação que haverá essa semana aqui na Enercon?

Gael logo perguntou: 
- Nós que somos terceirizados da Edifica LTDA, trabalhando aqui na Enercon, podemos participar?

- Infelizmente não. A campanha só vale para os funcionários da Enercon - Eliana respondeu.

Gael disse com ironia para mim, Amanda e Marcela, mas sem que Eliana ouvisse:

- Meu Deus, nossa situação está complicada, viu?! Semana passada houve essa mesma campanha na Edifica LTDA e nós não pudemos participar porque não fomos autorizados a sair da Enercon.

Meses depois daquele 05 de agosto, o fim de ano se aproximava e junto com ele as esperadas confraternizações. Faltando 20 dias para o Natal, Eliana avisou ao pessoal que a secretária do departamento estava pedindo para enviar uma lista com os nomes dos funcionários que estariam interessados em participar do jantar de confraternização do departamento. Mas frisou que, infelizmente, a equipe da Edifica LTDA não poderia participar, porque a Enercon iria pagar uma parte do valor do jantar de cada funcionário. Eu logo respondi:

- Nossa, se o problema fosse esse, nós faríamos questão de pagar nossa parte! Só faltou consideração com a presença da nossa equipe nessa empresa. Estamos há quatro anos aqui e ainda tem gente que não sabe da nossa existência!

- É... Também fico triste por não participarem, não faço distinção com vocês, mas infelizmente não tenho autonomia para mudar essa situação - Eliana respondeu, solidária.

Com a virada de ano, houve uma mudança de coordenação. Társio, o novo coordenador, não achava necessária a presença da equipe da Edifica LTDA para executar as atividades na Enercon, e marcou uma reunião com um componente da equipe da Edifica LTDA, a coordenadora e o supervisor, e eu fui a escolhida.

- Samara, você realmente acha necessária a presença da equipe Edifica LTDA dentro da Enercon para desenvolver suas atividades? - Társio me questionou.

- As atividades podem ser feitas fora daqui, porém as entregas serão mais lentas, tendo em vista que temos que tirar dúvidas com o pessoal da Enercon. Se você quiser fazer o teste, pode ficar à vontade, mas eu não garanto que a nossa produtividade será a mesma - eu respondi.

Voltei da reunião muito pensativa e, ao comentar com as colegas da equipe como foi a reunião, desabafei:

- Pessoal, não suporto mais essa situação de não pertencer a nenhuma empresa. Na Edifica LTDA, o RH esquece que existe uma equipe terceirizada, e na Enercon me sinto apenas mão de obra. Na Edifica LTDA não tenho perspectiva de desenvolver minha carreira, meu desempenho não é avaliado, não recebo feedback do meu trabalho, não participo das ações que o setor de recursos humanos proporciona para os funcionários que estão na sede. $\mathrm{Na}$ Enercon me sinto acuada, sem ser valorizada. Ainda por cima, esse novo coordenador quer que apenas um de nós, provavelmente eu, permaneça aqui. Mesmo assim, eu amo o que faço, pois me identifico demais com esse trabalho, que no geral é muito bom.

Nesse momento da história, Samara ponderou outras questões com sua antiga professora:

- Porém, professora, ao analisar o cenário profissional de João Pessoa, já que a Edifica LTDA é a única organização na cidade em que eu posso atuar na minha área, fico pensando se seria inteligente redirecionar minha carreira. Teria que começar praticamente do zero se quisesse continuar morando aqui. Será que eu estaria disposta a procurar emprego em outra cidade? Acabei de financiar um apartamento, e isso também me angustia, porque preciso ter 
condições financeiras de arcar com esse investimento. No mundo ideal, a Edifica LTDA podia encerrar meu contrato como terceira na Enercon, e me reintegrar em seu quadro de funcionários. Mas, com isso eu não posso contar. Já sei que eu fui solicitada para permanecer na Enercon, sem outra opção além de tomar uma decisão sobre minha carreira. Ai, não sei mesmo o que fazer...

\section{EU TERCEIRIZADA: O DESAFIO DE PERTENCER A DUAS EMPRESAS E NÃO PERTECER A NENHUMA}

No ano de 2010, com 16 anos de idade, entrei no Instituto Federal da Paraíba para fazer o curso técnico em edificações, o que era a realização de um sonho, tanto meu, quanto dos meus pais. Naquele momento, eu teria o primeiro contato com uma possível carreira profissional, tendo em vista o direcionamento que o curso proporcionava ao aluno. Eram quatro anos de curso, e a partir do segundo já podíamos estagiar, o que para mim era ótimo. Com 18 anos, ingressei no mercado de trabalho na área em que estudava, de modo que eu podia explorar os caminhos que queria trilhar.

Em agosto de 2012, comecei no meu primeiro estágio, e estava muito empolgada, pois sempre fui muito comunicativa, conseguia me adaptar com facilidade às situações enfrentadas e me entrosar com as pessoas, sendo o estágio um lugar onde eu construiria um novo ciclo de amizades. Passados três meses, em novembro de 2012, consegui um emprego em uma empreiteira na área em que estudava, com carga horária de 6 horas corridas, o que considerei ótimo, pois eu conseguiria trabalhar e estudar. No entanto, passei somente seis meses nessa empresa, pois era um contrato temporário.

Em maio de 2013, desempregada, a Edifica LTDA me fez uma oferta de estágio, que prontamente aceitei. Como estagiária, tive a oportunidade de trabalhar no fim de um projeto e início de outro, para, após seis meses, ainda no ano de 2013, ser contratada como efetiva no quadro de funcionários da empresa.

A Edifica LTDA está presente em mais de 10 Estados do Brasil, e há mais de dez anos atua no mercado prestando serviços na área de obras civis. A empresa iniciou suas atividades com aproximadamente 40 funcionários e, em 2020, emprega mais de 400 colaboradores especializados, com formação em diversas áreas. A missão da empresa é o compromisso com a qualidade dos serviços e a satisfação dos clientes. Tem a Enercon como sua principal contratante, e as duas empresas possuem essa parceria há 10 anos, tanto no que diz respeito ao trabalho de escritório, quanto ao trabalho em campo.

O Grupo Enercon possui 15 unidades, localizadas em vários Estados do Brasil. Presente em 788 municípios, emprega mais de 10 mil colaboradores e atende cerca de 16 milhões de consumidores, o que corresponde a $7 \%$ da população brasileira. Inovação e credibilidade são atributos que definem o Grupo Enercon. Dentro de suas atividades, a atualização da base de dados tem um grau de importância elevado, pois é por meio desta que as equipes de campo atuam. Essa atividade é realizada por um grupo pequeno de funcionários terceirizados da Edifica LTDA, empresa contratada, que são vinculados ao departamento de obras, o maior da Enercon.

Em meados de julho de 2014, a Enercon solicitou à Edifica LTDA o envio de dois técnicos para atender uma demanda dentro de sua sede. Nesse cenário, João, meu coordenador, chamou Amanda e eu para nos informar sobre essa nova demanda e que nós teríamos que trabalhar dentro da sede da Enercon por um período de três a seis meses. Ele justificou que fomos as escolhidas pelo nosso comprometimento e pelas nossas habilidades 
técnicas mais apuradas. No primeiro momento nós não gostamos da ideia de terceirizar fora da sede da nossa empresa, porém não tínhamos como negar.

Iniciaram-se então os treinamentos no sistema que iríamos trabalhar. Foram duas semanas turbulentas de treinamento, uma vez que havia certa rejeição da nossa parte, pois era um sistema totalmente diferente do que estávamos acostumadas a trabalhar, e isso nos tirava totalmente da nossa zona de conforto. Nessas semanas turbulentas, eu pensei até em pedir demissão, mas pensei melhor e decidi continuar. Enxerguei uma oportunidade de adquirir novos conhecimentos técnicos e vivenciar um outro tipo de ambiente organizacional com uma perspectiva de desenvolver melhor minha carreira, pois, afinal, estava indo compartilhar a realidade de um grupo de grande porte com uma rotina e gestão diferente da que eu estava acostumada; não podia deixar que o medo do novo me impedisse de conhecer outras realidades. Após duas semanas de treinamento, fomos para Enercon um pouco apreensivas, com receio de não conseguirmos atender às expectativas.

Ao chegarmos no departamento em que trabalharíamos, deparamo-nos com uma sala enorme com cerca de 20 pessoas, que nos receberam bem. Porém, fomos colocadas para trabalhar em computadores bem sucateados e, por conta disso, com o passar do tempo nossa produção não melhorava, motivo pelo qual a pressão era muito grande por parte da coordenação da Enercon, que realizava reuniões semanais para saber o porquê da nossa produção não evoluir.

Depois de muita insistência, conseguimos computadores novos, mas sinalizamos que apenas duas pessoas não eram suficientes para atender um passivo que já estava acumulado antes da nossa chegada, então a Edifica LTDA enviou mais duas pessoas para nos ajudar, formando um núcleo de quatro terceirizados: Amanda, Gael, Marcela e eu. Passaram-se os três meses iniciais, e mesmo com quatro pessoas e computadores novos, nossa demanda era contínua. Logo, após os seis meses desde que eu e Amanda havíamos chegado na Enercon, não existia previsão de volta para Edifica LTDA.

O lugar onde trabalhávamos, o departamento de obras da Enercon, era muito grande e possuía várias supervisões, por isso era dividido em duas salas. Ficávamos na sala menor, com a supervisão de cadastro, atividade que reunia cerca de 20 pessoas. O clima na nossa sala era muito tranquilo e, como fomos bem recebidos de início, com o passar do tempo fomos nos sentindo mais à vontade. Além disso, fomos nos adaptando com o tipo de gestão da empresa, pois éramos cobrados de uma forma diferente dos demais funcionários, já que tínhamos compromissos e exigências tanto da empresa contratante, como da contratada.

Entretanto, havia momentos em que nos sentíamos desvalorizados nas duas empresas, principalmente por questões relacionadas aos benefícios e relacionamentos interpessoais, o que fomentou um sentimento de não pertencermos a nenhuma empresa. Certo dia, na volta do almoço, Marcela chegou muito irritada relatando que havia almoçado com Lucas, também funcionário da Edifica LTDA, e ele inocentemente a perguntou:

- Você vai participar da confraternização da Edifica LTDA?

Tentando disfarçar sua surpresa, Marcela respondeu:

- Não, eu não fui informada sobre o evento...

Lucas ficou claramente desconfortável com a situação, pois todos que trabalhavam tanto na sede quanto no campo tinham sido comunicados, por isso ele não entendia por qual motivo nós que ficávamos na Enercon não fomos informados. Essa segregação sempre acontecia em momentos pontuais nas duas empresas. Por exemplo, na entrega de kit's natalinos no fim do ano na Enercon, éramos apenas quatro pessoas, mas sempre alegavam 
que a quantidade de kit's era exata para apenas os funcionários próprios, o que caracterizava uma não consideração acerca dos terceiros.

Todavia, momentos bons também aconteciam e precisavam ser valorizados. $O$ fato da equipe ser mesclada não impedia que tivéssemos uma boa convivência. Criamos uma relação de amizade e parceria muito harmoniosa com a supervisão de cadastro, aprendemos muito sobre o comportamento de um profissional, como também usufruíamos de alguns benefícios disponibilizados, como os ônibus fretados pela empresa para a locomoção dos funcionários.

\section{EU CONTINUO TERCEIRIZADA OU NÃO?}

Quando fui solicitada para terceirizar minhas atividades em outra empresa, no primeiro momento não aceitei muito bem a ideia, apesar de ser uma pessoa comunicativa e com facilidades de fazer amizades; porém, tentei enxergar esse novo desafio como uma oportunidade de crescimento. Quando cheguei à Enercon, havia momentos que eu tinha que ficar me policiando sobre a possibilidade de realizar ou utilizar algo, sobre ter direito de participar de alguma campanha, e essas dúvidas também se faziam presentes no meu relacionamento com a Edifica LTDA, empresa que eu devia sentir que fazia parte.

Essa situação fazia com que eu não me sentisse estimulada para trabalhar, pelo contrário, despertava um sentimento de raiva e abandono. Em consequência disso, havia momentos em que eu sentia que não me empenhava para realizar minhas atividades, pois sabia que não seria reconhecida pelo meu esforço por nenhuma das duas empresas. Portanto, em muitas situações eu me perguntava: será que eu sou apenas mão de obra? Onde eu pertenço? Mas, mesmo assim, ia seguindo porque o trabalho tinha uma boa remuneração, minha equipe era coesa e tínhamos alguns benefícios que ainda faziam valer a pena insistir, mesmo que poucos comparados com os que os funcionários Enercon e Edifica LTDA tinham.

No entanto, após quatro anos prestando serviço na Enercon, houve uma mudança de coordenação e, com isso, ficou decidido que apenas uma pessoa ficaria na sede, e eu fui a escolhida para continuar; o resto da equipe iria voltar para a Edifica LTDA. Fiquei preocupada, pois toda responsabilidade que antes era dividida por quatro pessoas ficaria centralizada em mim. Pensava em como seria ficar só e lidar com as adversidades do dia a dia, pois com toda equipe reunida o estresse da rotina era amenizado, e eu pensava que iria me sentir deslocada, talvez até isolada. Com a partida da minha equipe, estranhei bastante a rotina diferente: as horas demoravam a passar e, como já era previsto, sentia muito a falta dos meus colegas.

No auge da minha angústia, a Enercon passava por um momento festivo, pois se destacava como uma das sete melhores empresa da Paraíba para se trabalhar. Havia uma agitação e muita especulação sobre como seria a comemoração desse prêmio e, depois de muitos boatos, o convite da festa foi divulgado. Mas, para minha surpresa, o convite destacava, com letras garrafais, que a festa seria EXCLUSIVA para funcionários próprios e a entrada seria mediante apresentação do crachá, o que mais uma vez me excluía.

Nesse momento, pressionada pela partida dos meus amigos, pelas insatisfações que ser terceira estavam me causando há bastante tempo, e pela incerteza de mudança dessa relação no futuro, eu me questionava se deveria permanecer nessa situação. Ao mesmo tempo, dificilmente eu encontraria um outro emprego que tivesse a remuneração adequada na área técnica, e eu tinha acabado de comprar um apartamento e precisava dessa estabilidade financeira.

Só que o descobrimento de um fato me deixou ainda mais revoltada. Uma colega da Edifica LTDA revelou que nós, técnicos terceiros na Enercon, tínhamos uma espécie de "passe", ou seja, nosso valor financeiro para a Enercon variava de acordo com as nossas 
habilidades. Isso significava que, a depender do terceiro, a Edifica LTDA recebia de $\mathrm{R} \$ 7.000,00$ a $\mathrm{R} \$ 18.000,00$. Muitas vezes a Enercon solicitava um terceiro específico, e a Edifica LTDA negociava seu "passe". Mas esses valores não eram repassados para nós; sequer sabíamos disso. $O$ passe sendo $\mathrm{R} \$ 7.000,00$, o terceiro recebia no máximo $\mathrm{R} \$ 1.300,00$ líquido. Isso era um absurdo!

Diante desses fatos, eu fiquei cada vez mais desmotivada. Será que eu aguentaria ser invisível por muito mais tempo na Enercon? E essa desconsideração da Edifica LTDA, como me afetava? Eu sabia que precisava tomar uma decisão: aceitar a situação como ela era, ou tentar seleção para outra área, mesmo que o salário fosse ainda menor e os benefícios mais escassos, tendo que desistir de todo o aprendizado e crescimento que obtive nesses anos todos. No nosso estado não havia concorrentes diretos da Edifica LTDA, e isso me deixava sem muitas opções de carreira. Assim, eu me questiono a todo tempo: O que é que eu devo fazer?

\section{NOTAS DE ENSINO}

\subsection{OBJETIVOS EDUCACIONAIS}

O caso foi elaborado para debater questões relativas às condições de trabalho de terceirizados e a decisões de carreira, apresentando uma situação que pode fazer a protagonista ter que reencaminhar seu planejamento profissional. Desse modo, tem como objetivo que o aluno entenda que quando há uma parceira de terceirização, a gestão de pessoas terceirizadas deve ser realizada por ambas as organizações, propiciando um envolvimento emocional, inconsciente e subjetivo, para que de fato possa significar uma vantagem competitiva. Neste sentido, entendemos que é também papel das empresas ajudar seus funcionários a se sentirem pertencentes ao todo, uma vez que este sentimento tem se tornado cada vez mais esporádico, o que pode prejudicar a manutenção do terceiro na organização contratante. Quanto às questões de decisão de carreira, propomos uma discussão acerca das âncoras individuais que direcionam o interesse profissional, bem como os dilemas que podem surgir em determinado contexto de trabalho. Diante disso, a aplicação do caso é sugerida em cursos de graduação e pós-graduação lato sensu em Administração nas disciplinas de gestão de pessoas, especificamente na discussão de elementos relacionados ao planejamento de carreira.

No que diz respeito às competências a serem desenvolvidas nos alunos, acreditamos ser importante a compreensão da gestão em diversos contextos organizacionais, sendo a terceirização um deles, bem como das possibilidades de carreira que devem ser consideradas ao longo do percurso profissional. Dito isso, especificamente, pretendemos que os alunos possam, por meio da aplicação do caso, (1) compreender as especificidades da gestão de pessoas terceirizadas, pela ótica desse tipo de trabalhador, e (2) aprender sobre a aplicação das âncoras de carreira como possível suporte para decisões de carreira.

\subsection{FONTE DE DADOS}

Este caso é real e se baseia na experiência da protagonista como terceira, de modo que a coleta de dados foi prioritariamente por observação participante. 0 caso relata situações que a protagonista vivenciou, bem como seus colegas. O nome das empresas e dos personagens, inclusive da protagonista, foram alterados com o intuito de garantir o seu anonimato. 


\subsection{TÓPICOS PEDAGÓGICOS}

Para a aplicação desse caso, sugerimos os seguintes passos:

1. O professor deve explicar aos alunos os procedimentos para utilização do caso para ensino em sala de aula;

2. O professor deve requerer a prévia leitura individual do caso como atividade, bem como cobrar dos alunos respostas individuais às questões propostas;

3. Na aula seguinte à explicação da metodologia e leitura do caso, o professor deve estimular que, em pequenos grupos de 3 a 4 pessoas, os alunos debatam e discutam as respostas das questões descritas no caso;

4. Após discussão nos pequenos grupos, sugerimos dispor a turma em um círculo e solicitar que cada grupo apresente oralmente a sua análise, cabendo ao professor estimular a participação dos alunos;

5. O professor deve realizar um fechamento do caso para ensino estudado, propondo direcionamentos para análise a partir das opiniões manifestadas pelos alunos e discutindo as alternativas propostas por eles. O professor pode, inclusive, utilizar o quadro para elencar as alternativas propostas pelos alunos, de modo a ficar visível para toda a turma.

Por fim, salientamos a opção pela não delimitação de tempo para cada etapa sugerida para aplicação do caso para ensino, uma vez que cada turma tem características heterogêneas que devem ser consideradas. Com isso, sugerimos que o professor possa decidir acerca da sistemática que melhor se adapta à condução do caso para ensino em sala de aula.

\subsection{QUESTÕES PARA DISCUSSÃO}

1. Com base no caso, qual a análise das condições de trabalho da equipe de Samara, considerando que seus membros eram funcionários terceirizados?

2. Como você avalia a relação entre a identidade organizacional e as estratégias de gestão de pessoas utilizadas pelas duas empresas envolvidas, a Enercon (contratante) e a Edifica LTDA (contratada)? Apresente elementos do caso para justificar sua resposta.

3. A partir das características descritas no caso, quais âncoras de carreira predominam no perfil de Samara?

4. Digamos que você é Samara. Qual seria sua decisão para o dilema de continuar ou não terceirizada? Fundamente sua resposta.

\subsection{ANÁLISE DO CASO E CONEXÃO COM A LITERATURA}

\section{Com base no caso, qual a análise das condições de trabalho da equipe de Samara, considerando que seus membros eram funcionários terceirizados?}

Nessa questão, o aluno deve compreender as particularidades das relações de trabalho que são impostas, em geral, no contexto da terceirização. Inicialmente, o aluno pode apontar que a combinação de culturas, que fatalmente ocorre em processos de terceirização, é algo que pode afetar as condições de trabalho do ambiente organizacional terceirizado, impactando no trabalho desses funcionários.

Para Leiria, Fontanella e Tavares (1994), mesmo que haja uma provável complementaridade cultural, a possibilidade de haver a dominação de uma cultura sobre a outra ou uma incompatibilidade de convívio acarreta uma queda de produtividade ou ruptura no relacionamento entre as duas organizações. É importante mencionar que atores organizacionais provenientes das empresas terceirizadas com cultura e valores distintos da 
contratante podem se sentir desconfortáveis e mesmo desvalorizados nos ambientes de trabalho da empresa contratante, gerando baixa qualidade do clima organizacional e produtividade, e influenciando inclusive os resultados dos funcionários da empresa contratante. No caso retratado, não é possível destacar uma combinação de culturas, tendo em vista a presença de apenas quatro terceirizados na Enercon.

Para identificar outras evidências, o aluno pode se embasar no trabalho de Pinto e Quelhas (2008), que apresenta dados de uma pesquisa com terceirizados, os quais revelam os aspectos negativos mais frequentes sobre suas condições de trabalho, como: (1) programa de treinamento exclusivo para funcionários contratados; (2) exclusão nas atividades sociais da contratante, como festas e comemorações em geral; (3) recebimento de equipamento inferior ou inadequado ao terceirizado; (4) proibição de participar de reuniões; (5) proibição de uso da infraestrutura da contratante, como restaurante, Internet ou telefone.

Sobre o primeiro ponto apontado por Pinto e Quelhas (2008), Magalhães, Carvalho e Saraiva (2011) afirmam que o tema qualificação é, ainda, alheio aos contratos de prestação de serviços, os quais se limitam, em regra, ao objeto, ao valor, aos prazos, às formas de controle e às obrigações das partes envolvidas. Dessa forma, a responsabilidade pela direção de processos de qualificação e comprometimento dos trabalhadores incide sobre os gestores que precisam propiciar ambiente e recursos de trabalho que sejam adequados aos profissionais com diferentes tipos de vínculos contratuais.

No caso, esse desafio também aparece ou fica subentendido, pois, a Enercon não se preocupou em realizar treinamento formal com os funcionários terceirizados, mesmo que a equipe terceirizada não tivesse conhecimento do programa que deveria ser utilizado por ela. Com efeito, segundo Fernandes e Carvalho Neto (2005), as condições de funcionários terceirizados, em geral mais vulneráveis, favorecem uma cultura de insegurança no trabalho e reafirmam o sentimento de não pertencimento. Isso é consequência também do baixo investimento em treinamento e desenvolvimento, da falta de transparência e precisão nas expectativas de desempenho e da ausência de acompanhamento e orientação ao trabalhador terceirizado.

Sobre a questão de não participação em atividades sociais da contratante, apesar da equipe de Samara possuir uma boa convivência com os colegas contratados diretamente, os fatos relatados no caso sobre a ausência de convite para festas e de participação na distribuição de brindes demonstram uma segregação também apontada na pesquisa revelada por Pinto e Quelhas (2008). Sobre isso, é possível reconhecer que os contratos de terceirização podem se tornar desafiadores para as organizações no que concerne à gestão de pessoas, pois é preciso considerar expectativas, necessidades e interesses dos terceiros para que eles possam se manter comprometidos, evitando o sentimento de não pertencimento. Nesse sentido, organizações contratantes precisam se preocupar com todos, irrestritamente, com os quais mantêm relações de trabalho, de modo que as suas políticas de pessoal alcancem a mão de obra terceirizada igualmente (PETEROSSI; SIMÕES; SANTOS, 2014).

A questão do fornecimento de equipamento inferior ou não adequado para o profissional terceirizado (PINTO; QUELHAS, 2008) também pode ser elencada, haja vista que local e equipamentos adequados para a realização do trabalho de Samara e Amanda, inicialmente, só foram providenciados depois da insistência de ambas, mediante argumento da sua necessidade para entrega de melhor desempenho. Sobre a exclusão em reuniões, não fica evidente que isso tenha acontecido com a equipe terceirizada, mas é possível deduzir que, se aos seus membros não era permitida a participação em eventos sociais, provavelmente não deveriam participar de reuniões gerais. Todavia, contrariamente à impossibilidade de 
utilização da infraestrutura da empresa contratante, mencionada por Pinto e Quelhas (2008), Samara relata que a equipe podia usufruir de alguns benefícios, como os ônibus fretados pela empresa para a locomoção dos funcionários.

Por fim, vale salientar que, apesar de o contratante ter como um dos objetivos da terceirização um menor custo operacional, e do fato de a contratação desse tipo de mão de obra ser implicitamente mais barata (PETEROSSI; SIMÕES; SANTOS, 2014), a descoberta do valor cobrado pela Edifica LTDA à Enercon pelo serviço terceirizado da equipe de Samara, sem que fosse repassado nem $10 \%$ aos seus membros, foi outra situação que desvendou uma condição desestimulante para o terceiro. Nesse caso, parece que a parceria se estabelece apenas entre contratante e contratada, sem considerar que o terceiro é o elo, o qual precisa de uma gestão e remuneração mais adequadas ao seu papel em ambas as empresas.

\section{Como você avalia a relação entre a identidade organizacional e as estratégias de gestão de pessoas utilizadas pelas duas empresas envolvidas, a Enercon (contratante) e a Edifica LTDA (contratada)? Apresente elementos do caso para justificar sua resposta.}

Nessa questão, o aluno pode argumentar que as políticas de gestão de pessoas da empresa contratante devem alcançar a mão de obra terceirizada, de modo que é preciso estabelecer, no instrumento de contrato, mecanismos que permitam que isso ocorra de maneira eficaz (TACHIZAWA; FERREIRA; FORTUNA, 2001). Embora ainda pareçam acanhadas, nas iniciativas das organizações brasileiras, no que diz respeito à gestão dos terceirizados, há exemplos que significam preocupação em lidar com os desafios colocados pelo ambiente da terceirização (FERNANDES; CARVALHO NETO, 2005).

Conforme Fernandes e Carvalho Neto (2005), a fim de sanar tais desafios, algumas estratégias podem ser elencadas: (1) as empresas têm investido na definição de critérios, políticas e regras para orientarem a gestão do contrato de terceiros; (2) a contratante passa a orientar os processos de seleção dos terceirizados por meio da contratação e negociação de metas e pelo acompanhamento e avaliação do desempenho em conjunto com a contratada; (3) os terceiros são integrados aos processos de treinamento e desenvolvimento da contratante com vistas a lidar com a questão da capacitação de trabalhadores terceiros; (4) a avaliação de metas, a supervisão e o feedback passam a ter como objetivo a garantia de melhoria dos serviços; (5) os terceiros são envolvidos no planejamento de trabalho e na troca de experiências; e (6) processos estruturados de certificação para as empresas terceirizadas são estabelecidos

Nesse contexto de terceirização, todas essas medidas deveriam ser adotadas pelas organizações envolvidas para superar os desafios impostos pela terceirização dos serviços, pois a gestão de pessoas precisa assumir um comportamento estratégico, a fim de que os indivíduos passem a ter um vínculo com a organização. Esse vínculo caracteriza a identidade organizacional, que é a ligação psíquica do indivíduo com a organização (MACHADO, 2003). Contudo, na equipe de Samara não é possível identificar uma identidade organizacional, que orienta a ação dos indivíduos e é dinamicamente construída por meio de interações sociais, identificações e afiliações (MACHADO, 2003).

Isso porque, a equipe de Samara não é lembrada nem pela Edifica LTDA e tampouco pela Enercon nos momentos de festa e confraternização. Além disso, os terceiros realizam o trabalho na Enercon, mas a empresa não oferece treinamento para a equipe, já que seu vínculo trabalhista é com a Edifica LTDA, o que fica claro, pois antes de irem para a Enercon, Samara e Amanda foram treinadas na Edifica LTDA. Outro ponto relevante se refere à falta de políticas de avaliação de desempenho da Edifica LTDA no que diz respeito ao trabalho da

RGO - Revista Gestão Organizacional, Chapecó, v. 14, n. 3, p. 143-157, set./dez. 2021. 
equipe terceirizada, uma vez que esta atua na prestação de serviço por um longo período na Enercon, que também não aplica avaliações formais, fazendo com que a equipe perca qualquer oportunidade de feedback sobre seu desempenho e possíveis promoções.

Assim, no caso da equipe de Samara, o máximo que podemos observar é uma identidade no trabalho, que está vinculada ao processo afetivo de identificação, e que ocorre por meio das relações estabelecidas entre os membros do grupo de pertença na Enercon, o que permite a assimilação da mentalidade, das regras e das normas da contratante (NASCIMENTO et al. 2013). Essa identidade no trabalho aparece no momento em que Samara afirma que foi bem recebida na Enercon, que tinha boa relação interpessoal com a sua equipe da Edifica LTDA e também com a equipe da Enercon, mas isso não se configura como identidade organizacional.

Percebemos, portanto, que a boa recepção por parte da equipe de trabalho direta da Enercon ajudou na construção da identidade no trabalho, evitando que ocorra o que apontam Magalhães, Carvalho Neto e Gonçalves (2010) sobre os trabalhadores terceirizados em geral serem alvo de tratamento preconceituoso, consequência de um ponto de vista estereotipado que os qualifica como possuindo baixo conhecimento, pouca qualificação, pouca ética no trabalho e como inferiores em relação aos trabalhadores das contratantes. Para Barbosa (2010), a todos esses fatores soma-se o distanciamento do sentimento de estabilidade que conduziria a uma inserção social por meio do trabalho.

Com isso, o aluno pode apontar que Samara e os demais terceiros, ao não se identificarem com nenhuma das duas empresas, criaram uma identidade social restrita, que resultou de um sentimento de pertencimento à equipe terceirizada. Com a saída de seus colegas, esse grupo de identificação foi desfeito, o que desmotivou ainda mais Samara, que perdeu esse sentimento de pertencimento. A carência desse estímulo, por falta de gestão apropriada, pode desencadear alguns impactos negativos, como por exemplo, esgotamento, desmotivação, produção baixa e insatisfação no trabalho, fatos que ocorreram no caso de Samara e sua equipe.

\section{A partir das características pessoais de Samara que foram descritas no caso, quais são as âncoras de carreira predominantes da protagonista? Se ao invés de Samara, você fosse o protagonista dessa história, quais seriam as suas âncoras e como você planejaria sua carreira?}

Nessa questão, o aluno deverá identificar o perfil de Samara a partir da análise dos comportamentos apresentados por ela em cada uma das experiências vivenciadas no caso. Realizar essa identificação de perfil servirá de embasamento para reconhecer as âncoras de carreira que a personagem apresenta. As âncoras de carreira desenvolvidas por Schein (1993) compõem um conjunto de auto percepções associadas à maneira como o indivíduo lida com o seu trabalho, diz respeito à autoimagem da pessoa e influencia a maneira como ela lida com as experiências vivenciadas, sendo a âncora predominante aquela que o indivíduo não irá abrir mão na hora de tomar uma decisão de carreira (SCHEIN, 1993; MOREIRA; ARAÚJO, 2018).

É imprescindível que o aluno conheça as âncoras de carreira para poder responder à questão de maneira adequada. Assim, o professor precisará apresentar as âncoras de carreira (Quadro 1) para os alunos, de acordo com Schein (1993). Ainda, para aprofundar o conhecimento sobre gestão de carreira e âncoras, o aluno pode tomar como base o estudo de Tieppo et al. (2011). 
Quadro 1 - Âncoras de carreira

\begin{tabular}{|l|l|}
\hline \multicolumn{1}{|c|}{ Âncoras } & \multicolumn{1}{|c|}{ Descrição da âncora } \\
\hline Competência técnica/funcional & $\begin{array}{l}\text { Nesta âncora, a pessoa sente-se totalmente realizada quando o } \\
\text { trabalho permite enfrentar fortes desafios em áreas técnicas. }\end{array}$ \\
\hline Competência gerência geral & $\begin{array}{l}\text { Relaciona-se com a perspectiva de responsabilidade absoluta por } \\
\text { resultados e identificação do próprio trabalho com o sucesso da } \\
\text { organização. }\end{array}$ \\
\hline Segurança/estabilidade & $\begin{array}{l}\text { Nesta âncora, as pessoas não são tolerantes a regras e restrições } \\
\text { organizacionais. As pessoas preferem recusar promoções a perder } \\
\text { autonomia. }\end{array}$ \\
\hline Criatividade empreendedora & $\begin{array}{l}\text { A principal preocupação nesta âncora é alcançar a sensação de ser bem- } \\
\text { sucedido para ficar tranquilo. }\end{array}$ \\
\hline Serviço/dedicação a uma causa & $\begin{array}{l}\text { Nesta âncora o alvo é sempre a procura por oportunidades futuras, com } \\
\text { a pessoa trilhando um caminho próprio assim que identificar condições } \\
\text { para tal. }\end{array}$ \\
\hline Puro desafio & $\begin{array}{l}\text { Nesta âncora, não há renúncia, em qualquer hipótese, a oportunidades } \\
\text { de trabalho em que se realize algo útil. }\end{array}$ \\
\hline Estilo de vida & $\begin{array}{l}\text { Nesta âncora a pessoa costuma não abrir mão de oportunidades de } \\
\text { trabalho na solução de problemas aparentemente insolúveis, vencendo } \\
\text { oponentes duros ou obstáculos difíceis. }\end{array}$ \\
\hline
\end{tabular}

Fonte: adaptado de Schein (1993).

A partir da descrição das características de Samara e de suas atitudes frente às experiências vivenciadas no caso e do conhecimento das âncoras de carreira, o aluno será capaz de identificar que os fatos de ela aceitar sair de sua empresa para se tornar terceirizada em outra, executar uma atividade totalmente diferente daquela que está habituada e cogitar, a partir de sua insatisfação com as empresas, buscar outras oportunidades de trabalho, mesmo que com poucos benefícios salariais, demonstram um alinhamento com busca por desafios e motivação para se desenvolver tecnicamente. Com isso, é possível identificar que há uma tendência para que Samara tenha como âncoras de carreira prioritárias, em primeiro lugar, aquela definida como desafio puro e, em segundo lugar, a competência técnica/ funcional.

Adicionalmente, essa questão tem o potencial de estimular os alunos a identificarem suas próprias âncoras de carreira, por meio da proposição de Schein (1993), colocando-se no lugar de Samara. Esse processo favorece também um melhor entendimento de como suas âncoras podem direcionar seu planejamento de carreira, visualizando, a partir do caso, possíveis acontecimentos que, como para Samara, levam a um dilema profissional que tem a capacidade de criar desvios para o que foi planejado inicialmente pelo indivíduo. Nesse sentido, é interessante que o aluno compreenda que, em casos de dilemas de carreira, tomar como base as suas âncoras, possibilita uma decisão mais assertiva em relação às suas expectativas

\section{Sabendo que Samara é da geração $Z$, e com base nas suas âncoras de carreira, qual a decisão que você acha mais provável que ela tome sobre o dilema que enfrenta?}

Nessa questão, o aluno deverá opinar e fundamentar sua resposta sobre o caminho que Samara, que é integrante da geração Z, deverá seguir. Para realizar essa discussão, é imprescindível que o aluno conheça as principais características dessa geração, como o elevado conhecimento tecnológico e o hábito de viver conectada à Internet e às redes sociais. Essa geração não conhece um mundo sem tecnologia referente a computadores e celulares 
com rápido acesso a informações (COLET; BECK; OLIVEIRA, 2015). Outras características dessa geração são a autoconfiança, o otimismo, o imediatismo, a capacidade de serem multitarefas, a busca pela satisfação no trabalho e o jeito de enxergar os desafios como etapa inerente ao sucesso (MELO et al. 2019).

Conhecendo o perfil de Samara, a partir das suas âncoras e do fato de ela ser integrante da geração Z, cabe ao aluno deliberar sobre as opções que ela possui. Os caminhos mais visíveis são continuar terceira mesmo sem estímulos para criar uma identidade organizacional e um sentimento de pertencimento a uma organização ou buscar novas oportunidades de trabalho em outros lugares onde ela possa se sentir parte da empresa, mesmo que os benefícios financeiros sejam inferiores, mas isso não impede de o aluno opinar sobre outras probabilidades.

A questão, portanto, direciona para uma discussão sobre carreira, na medida em que Samara se depara com a possibilidade de, ao sair da Edifica LTDA, não encontrar outra organização semelhante para aplicar seus conhecimentos técnicos e práticos. Desse modo, é interessante que o aluno entenda que o planejamento da carreira e sua gestão tende a se adequar às características de Samara, e que o caminho escolhido precisará levar em conta a adaptação dela no contexto profissional.

Algumas opções sugeridas podem levar em consideração a possibilidade de Samara mudar de localidade para uma outra cidade que tenha mais opções na função que ela atua, ou mudar de área, ou tentar alguma seleção para a própria Enercon. Para incrementar a discussão, o aluno pode ainda se apoiar em Mendonça et al. (2020), que revelam que jovens concluintes da geração $Z$, apesar de se sentirem confiantes sobre sua empregabilidade, demonstram preocupação quando precisam procurar um novo emprego. A intenção é que o aluno perceba todos esses encaminhamentos que a situação vivenciada por Samara pode tomar, sem que, necessariamente, haja uma resposta certa e definitiva.

\section{BIBLIOGRAFIA RECOMENDADA}

DUTRA, J. S. Gestão de Carreiras. A Pessoa, a Organização e as Oportunidades. São Paulo. Atlas, 2017.

LEIRIA, J. S.; FONTANELLA, D.; TAVARES, E. O Lado (des)humano da terceirização. Salvador: Casa da Qualidade, 1994.

MAGALHÃES, Y. T.; CARVALHO NETO, A. M.; GONÇALVES, P. P. B. Os múltiplos desafios da gestão de terceirizados: a experiência dos gestores de contratos. Revista de Ciências da Administração, v. 12, n. 26, p. 116-143, jan/abr. 2010. https://doi.org/10.5007/21758077.2010v12n26p116.

MAGALHÃES, Y. T.; CARVALHO NETO, A. M; SARAIVA, L. A. S. Práticas gerenciais relacionadas à qualificação de trabalhadores terceirizados: um estudo de caso no setor de mineração. Organizações \& Sociedade, v. 18, n. 57, p. $227-$ 244, abr/jun. 2011. https://doi.org/10.1590/S1984-92302011000200002.

MACHADO, H. V. A identidade e o Contexto Organizacional: Perspectivas de Análise. Revista de Administração Contemporânea, v. 7, n. especial, p. 51-73, 2003. https://doi.org/10.1590/S1415-65552003000500004. 
MELO, A. O.; TAVARES, M. V. B.; FELIX, B. S.; SANTOS, A. C. B. D. Identidade da Geração Z na Gestão de 'Startups'. Revista Alcance, v. 26, n. 3, p. 320-333, set/dez. 2019. https://doi.org/10.14210/alcance.v26n3(Set/Dez).p320-333.

MOREIRA, S. A. S.; ARAUJO, B. F. V. B. Homens e Mulheres da Geração Y e suas Âncoras de Carreira. Desenvolvimento em Questão, v. 16, n. 42, p. 621-650, jan/mar. 2018. https://doi.org/10.21527/2237-6453.2018.42.621-650.

PETEROSSI, H. G.; SIMÕES, E. A.; SANTOS, M. L. N. Gestão de pessoas nos contratos de terceirização. Revista Gestão da Produção Operações e Sistemas, v. 9, n. 3, p. 131148, jul/set. 2014. https://doi.org/10.15675/gepros.v9i3.1058.

PINTO, M. F. F.; QUELHAS, O. L. G. Funcionários terceirizados: estudo da sua relevância para a organização brasileira. Revista da FAE, v. 11, n. 2, jul/dez. 2008.

RIBEIRO, R. P. D.; NUNES, S. C.; LOPES, H. E. G. As Carreiras Proteana e sem Fronteiras e as Âncoras de Carreira: Um Estudo com Profissionais da Área de Saúde em Minas Gerais. Gestão \& Regionalidade, v. 34, n. 102, p. 94-115, set/dez. 2018. https://doi.org/10.13037/gr.vol34n102.4249.

SCHEIN, E. H. Career Anchors: Discovering your real values. Revised Edition. San Diego: Pfeiffer \& Company, 1993.

TACHIZAWA, T.; FERREIRA, V. C. P.; FORTUNA, A. A. M. Gestão com pessoas: uma abordagem aplicada às estratégias de negócios. Rio de Janeiro: Editora FGV, 2001.

\section{REFERÊNCIAS}

BARBOSA, A. M. S. A naturalização da identidade social precarizada na indústria do alumínio primário paraense. Sociologias, v. 12, n. 23, p. 268-303, 2010.

https://doi.org/10.1590/S1517-45222010000100010.

COLET, D. S.; BECK, N.; OLIVEIRA, D. G. "Filhos da internet": desafios comportamentais da geração Z. In: Encontro de Gestão de Pessoas e Relações de Trabalho, 5, 2015, Salvador. Anais eletrônicos [...]. Salvador: Anpad, 2015.

FERNANDES, M. E. R; CARVALHO NETO, A. M. As práticas gerenciais frente aos principais desafios apontados pelas maiores empresas brasileiras na gestão de terceirizados. Encontro Anual da Associação Nacional de Pós-graduação e Pesquisa em Administração, 24, 2005, Brasília. Anais eletrônicos [...]. Brasília: ANPAD, 2005.

LEIRIA, J. S.; FONTANELLA, D.; TAVARES, E. O Lado (des)humano da terceirização. Salvador: Casa da Qualidade, 1994.

MACHADO, H. V. A identidade e o contexto organizacional: perspectivas de análise. Revista de Administração Contemporânea, v. 7, n. especial, p. 51-73, 2003.

https://doi.org/10.1590/S1415-65552003000500004. 
MAGALHÃES, Y. T.; CARVALHO NETO, A. M.; GONÇALVES, P. P. B. Os múltiplos desafios da gestão de terceirizados: a experiência dos gestores de contratos. Revista de Ciências da Administração, v. 12, n. 26, p. 116-143, jan/abr. 2010. https://doi.org/10.5007/21758077.2010v12n26p116.

MAGALHÃES, Y. T.; CARVALHO NETO, A. M; SARAIVA, L. A. S. Práticas gerenciais relacionadas à qualificação de trabalhadores terceirizados: um estudo de caso no setor de mineração. Organizações \& Sociedade, v. 18, n. 57, p. 227244, abr./jun. 2011. https://doi.org/10.1590/S1984-92302011000200002.

MELO, A. O.; TAVARES, M. V. B.; FELIX, B. S.; SANTOS, A. C. B. D. Identidade da Geração Z na Gestão de 'Startups'. Revista Alcance, v. 26, n. 3, p. 320-333, set/dez.

2019. https://doi.org/10.14210/alcance.v26n3(Set/Dez).p320-333.

MENDONÇA, A. V. F.; MATTOS, C. A. C.; LAURINHO, I. S.; FRANCO, B. S. N. Autoeficácia e autopercepção de empregabilidade: uma investigação entre concluintes do ensino superior. Revista Gestão Organizacional, v. 13, n. 2, p. 67-84, maio/ago. 2020. http://dx.doi.org/10.22277/rgo.v13i2

MOREIRA, S. A. S.; ARAUJO, B. F. V. B. Homens e mulheres da geração Y e suas âncoras de carreira. Desenvolvimento em Questão, v. 16, n. 42, p. 621-650, jan/mar. 2018. https://doi.org/10.21527/2237-6453.2018.42.621-650.

NASCIMENTO, T. G.; TORRES, C.V.; SOUSA, E. D. L; NASCIMENTO, D. A.; ADAID-CASTRO, B. G. Identidade no trabalho e a influência de aspectos sociodemográficos: um estudo da diferença entre grupos de policiais militares do Distrito Federal. Revista Brasileira de Segurança Pública, v. 2, n. 7, p. 90-117, ago/set. 2013.

PETEROSSI, H. G.; SIMÕES, E. A.; SANTOS, M. L. N. Gestão de pessoas nos contratos de terceirização. Revista Gestão da Produção Operações e Sistemas, v. 9, n. 3, p. 131148, jul/set. 2014. https://doi.org/10.15675/gepros.v9i3.1058.

PINTO, M. F. F.; QUELHAS, O. L. G. Funcionários terceirizados: estudo da sua relevância para a organização brasileira. Revista da FAE, v. 11, n. 2, jul/dez. 2008.

SCHEIN, E. H. Career Anchors: Discovering your real values. Revised Edition. San Diego: Pfeiffer \& Company, 1993.

TACHIZAWA, T.; FERREIRA, V. C. P.; FORTUNA, A. A. M. Gestão com pessoas: uma abordagem aplicada às estratégias de negócios. Rio de Janeiro: Editora FGV, 2001.

TIEPPO, C. E.; GOMES, D. F. N.; SALA, O. T. M.; TREVISAN, L. N. Seriam as âncoras de carreira aderentes às carreiras inteligentes? Estudo comparativo entre alunos formandos do curso de administração de empresas e turismo. Revista Gestão Organizacional, v. 4, n. 2, p. 144-154, jul/dez. 2011. 